This item was submitted to Loughborough's Research Repository by the author.

Items in Figshare are protected by copyright, with all rights reserved, unless otherwise indicated.

\title{
Quantification of buttock deformation on a rigid seat
}

\author{
PLEASE CITE THE PUBLISHED VERSION
}

https://doi.org/10.1007/978-3-030-20216-3_44

PUBLISHER

Springer

VERSION

AM (Accepted Manuscript)

\section{PUBLISHER STATEMENT}

This is a pre-copyedited version of a contribution published in HARRY, M., MARSHALL, R. and FRAY, M., 2019. Quantification of buttock deformation on a rigid seat. IN: Di Nicolantonio, M., Rossi E. and Alexander T. (eds). Advances in Additive Manufacturing, Modeling Systems and 3D Prototyping (AHFE 2019), Washington D.C., USA, 24-28 July 2019, pp.471-483. The definitive authenticated version is available online via https://doi.org/10.1007/978-3-030-20216-3_44.

\section{LICENCE}

CC BY-NC-ND 4.0

\section{REPOSITORY RECORD}

Harry, Michael, Russell Marshall, and Michael Fray. 2019. "Quantification of Buttock Deformation on a Rigid Seat". Loughborough University. https://hdl.handle.net/2134/37121. 


\title{
Quantification of Buttock Deformation on a Rigid Seat
}

\author{
Michael Harry ${ }^{1}$, Russell Marshall ${ }^{1}$ and Michael Fray ${ }^{1}$ \\ ${ }^{1}$ Loughborough Design School, Loughborough University, United Kingdom \\ $\{$ m.m.harry, r.marshall, m.j.fray\} @lboro.ac.uk
}

\begin{abstract}
The interaction between the human body and seats is a complex area of research. Due to the biological variation of soft tissues across human beings and the differences in research methods between investigators, the scientific knowledge on buttock deformation is inadequate. To achieve an objective characterization of how the buttock deforms during sitting, a new method was developed involving a motion capture system. With this method, correlations were identified between buttock compression and various anthropometric measurements obtained. Additionally, the method provided relevant insight into the variation in buttock deformation attributes across body-type categories. The results obtained were found applicable to digital human modelling, which is often used in the anthropometric assessment of various seated tasks.
\end{abstract}

Keywords: Digital Human Modelling • Buttock deformation · Seat design · Codamotion $\cdot$ Correlation analysis $\cdot$ Greater trochanter

\section{Introduction}

Seating is a common area of growing research [1], [2]. With an $8.8 \%$ increase in global sales volume of cars between the year 2015 and 2017 [3], and an increase of over 1 billion passengers carried by the world's airlines between 2013 and 2017 [4], the travel experience of both the driver and passenger(s) is important to stakeholders, especially the manufacturers. Seating constitutes a major part of this experience.

The comfort, safety, well-being, efficiency and productivity of seat users is dependent on the extent to which ergonomics is relevantly applied during the design process [5], [6]. Though an appreciable amount of research has been undertaken in seat design, there remains inadequate objective information about the sub-dermal soft tissue deformation experienced in the thigh-buttock region. Studies reveal various methods that have been utilized such as finite element modelling [7], [8], biomechanical modelling [9], interface pressure measurement [10], [11] and medical imaging technologies [12], [13]. The differences in research methods between investigators have led to differing results, due to the biological variation of soft tissues across human beings [14].

This study is part of a larger research directed at understanding the soft tissue deformation process during seating, and how to objectively quantify it. As the humanseat interaction is complex, the aim of this study was to develop a model that quantified how the buttock deformed, when contact was made with a rigid seat. In contrast to 
existing studies, this was based on understanding sub-dermal soft tissue deformation from an exterior perspective - by characterizing the behaviour of the outer buttock-thigh surface during different stages of sitting, in relation to human characteristics. As no similar technique was not found in existing literature, a novel research method was developed capable of achieving the aim of the study.

Digital Human Modelling (DHM) packages such as SAMMIE [15], RAMSIS [16] and Anybody [17] have been used to model a range of humans and to perform ergonomic assessment of fit, reach and vision of designs in a CAD environment. The findings from this study are relevant to DHM, in estimating soft tissue deformation during various seated tasks.

\section{Methods}

\subsection{Participants}

A total of forty-two (42) participants (34 males and 8 females) were recruited from the student population on a voluntary basis. The purpose and procedures of the study were explained by the researcher, and participants were required to sign an informed consent form before commencing the study. The trial protocol was approved by the Loughborough University Ethical Advisory Committee.

To ensure accurate body composition measurements, all participants were expected to adhere to the following conditions before their arrival:

- No eating of drinking 2 hours prior

- No vigorous exercise or body training 6 hours prior

- No alcohol consumption 24 hours prior

- No diuretics 3-4 days prior

- Urinate at least 30 minutes before

Those with any back or lower body related condition were excluded from the study.

\subsection{Anthropometric Measurement Procedure}

Thirty-one (31) body dimensions were obtained through physical measurement of the participants while other values were obtained using a body composition analyser. Measurements were taken three times and recorded. Consistency between measurements was ensured by recognizing anthropometric landmarks of the body and marking certain locations with a felt-pen to ensure precise values. Slight variations were observed between measurements, and the average was taken.

The posture of the participants and the techniques adopted for measuring each anthropometrical parameter were based on standard guidelines [18]. Measurements were taken using various anthropometric equipment. Body mass was measured in kilograms (kg) using an electronic scale (Mettler Toledo kcc150, Mettler Toledo, Leicester, UK, Resolution $1 \mathrm{~g}$ ) with accuracy of $0.001 \mathrm{~kg}$. Height was measured in millimetres $(\mathrm{mm})$ using a stadiometer. To ensure scientific uniformity, skinfold measurements were taken on the right side of the body, using a Holtain/Whitehouse skinfold calliper (Holtain Ltd. Crymych, UK). Girth, circumference and depth measurements were recorded to the 
nearest $0.1 \mathrm{~mm}$ with the aid of a measuring tape and Holtain Anthropometer, depending on what measurements were taken.

Body composition measurements such as body fat (\%), fat mass $(\mathrm{kg})$, muscle mass $(\mathrm{kg})$, body mass index (BMI) and physique rating were obtained using a Tanita body composition monitor. The device worked by sending an imperceptible current through the human body when the participant mounted the scale and gripped its handles. Only a minimal variation between measurements was observed, and the average was taken. As this was a study regarding seating and buttock deformation, additional skinfold measurements were taken from 3 non-standard sites around the buttock area (Fig. 1), namely: posterior suprailiac (a), lumbo-sacral (b) and gluteal crease (c). All measurements were performed by the researcher and are summarised in Table 1.

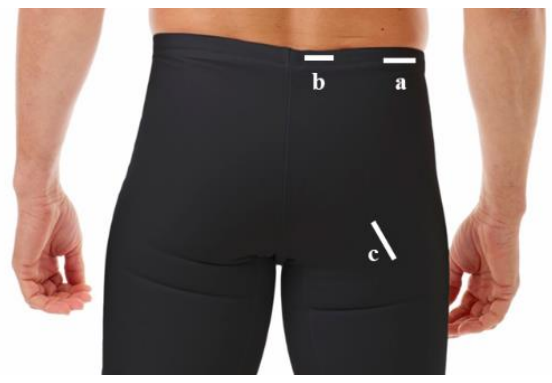

Fig. 1. Non-standard skinfold sites

Table 1. Anthropometric measurements

\begin{tabular}{|c|c|}
\hline General & Age, Mass, Height \\
\hline $\begin{array}{l}\text { Body } \\
\text { Composition }\end{array}$ & $\begin{array}{l}\% \text { Fat, Fat mass, Muscle mass, Bone mass, BMI, Physique } \\
\text { rating }\end{array}$ \\
\hline Skinfolds & $\begin{array}{l}\text { Pectoral, Midaxillary, Biceps, Triceps, Suprailiac, } \\
\text { Abdominal, Subscapular, Mid-thigh, Suprapatella, Medial } \\
\text { Calf, Posterior-Suprailiac, Lumbo-sacral and Gluteal Crease }\end{array}$ \\
\hline $\begin{array}{l}\text { Girths, } \\
\text { circumferences } \\
\text { and others }\end{array}$ & $\begin{array}{l}\text { Waist Girth, Waist Depth, Waist Breadth, Hip Girth, Hip } \\
\text { Depth, Hip Breadth, Bi-acromial Breadth, Buttock-knee } \\
\text { length, Knee height, Sitting height, Shoulder height (sitting), } \\
\text { Arm length and Hand length }\end{array}$ \\
\hline
\end{tabular}




\subsection{The Experiment Protocol}

As buttock deformation is difficult to measure due to the close contact between the primary areas of interest at the human-seat interface, a sitting trial protocol was designed with the following considerations:

- The material properties, dimensions and type of the trial seat that should be used

- A mechanism for supporting participants in a healthy and comfortable sitting posture that minimized the activation of the gluteal muscles and enabled soft tissues in the buttock-thigh area to deform freely or un-induced

- A scientific and reproducible technique for investigating the deformation process and acquiring relevant data for analysis

To satisfy these considerations, a trial rig was constructed, consisting:

- A mild steel seat frame ( $400 \mathrm{~mm}$ high) with a transparent polycarbonate seat pan $(700 \mathrm{~mm} \times 700 \mathrm{~mm})-$ to serve as a rigid seat. At its bottom, it had three notches that enabled the adjustment of the seat pan angle in $5^{\circ}$ increments from the horizontal. All seat dimensions were intended to accommodate both ends of the percentile spectrum, as the seating market is global.

- A flat wooden footrest with a foam padded cup-shaped knee rest - to avoid swinging of the body and gluteal muscle activation.

- A ceiling hoist (Guldmann UK) - to gently move participants upwards and downwards the seat pan in an upright sitting posture

- A chest strap (Guldmann UK) - to secure and support participants during the lift process

- A motion capture system (Codamotion) - to acquire a change in position of designated body spots, given its capability to digitally record human movement in a three-dimensional (3D) space for extended periods of time in various physical environments.

\subsubsection{Data Collection}

The Codamotion system was used as an instrument for acquiring data on buttock deformation. The Codamotion system is made up of markers, drive boxes, sensor units (CX1 CODA units), data analysis software (ODIN) and other accessories [19].

The markers acquire a unique 'marker ID' (such as Marker 1 or Marker 2) from the drive boxes, and they emit an infrared signal which is captured by optical sensors in the CX1 units. These units track the markers' position and 3D movement in real-time, with a latency of less than 0.5 milliseconds. This data is then transmitted to ODIN for recording and analysis. During the sitting trial, the markers (connected to the drive boxes) are attached to the designated buttock spots of investigation. The CX1 units operates normally when within $2.0 \mathrm{~m}$ and $4.5 \mathrm{~m}$ away from the markers, and they have a capture volume of approximately 75 cubic metres, with resolutions as high as 1 in 70,000 within its field of view.

Participants were provided with form-fitting leg tights or they could use their own if it was appropriately form-fitting. To objectively characterize buttock deformation, it was important to use an anatomical landmark as a reference point. The Greater Trochanter (GT) was chosen for its strategic location and distinct prominence around the 
hip region. Through palpation, the GT on the right side was located and marked with a sticker dot or chalk marker for all participants.

Participants were then asked to sit on a paper grid of angles placed on the seat pan, and they were held with the chest sling connected to the ceiling hoist. The purpose of this paper grid was to enable the investigator to attach the motion capture markers in $15^{\circ}$ increments from the greater trochanter (GT) rearwards across the right buttock. With the marked GT spot serving as the starting point $\left(0^{\circ}\right)$ for angular measurement, other locations on the same horizontal level were marked rearwards in $15^{\circ}$ increments. This was called the GT line (Fig. 2).

The alignment and positioning of markers on the buttocks was done with the aid of a combination square having a built-in bubble level. Using a pair of spring dividers and a set square, another horizontal array of markers 40mm below the GT line was created (GTX line). With the intended spots identified by dots, the motion capture markers were placed on them, as shown in Fig. 2.
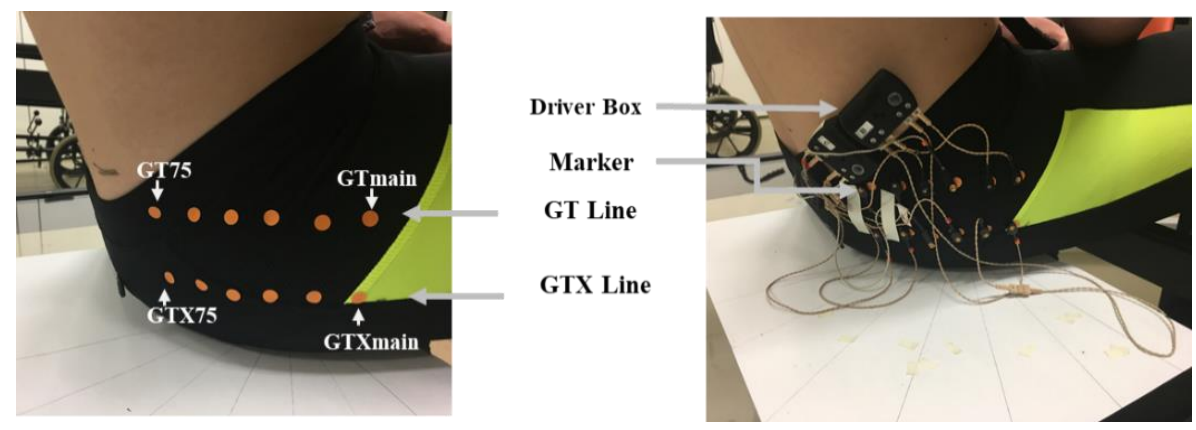

Fig. 2. The GT and GTX line marker location

Codamotion markers were also placed on other locations of the human body: acromion, the 7th cervical vertebra (C7), sacrum and lateral condyle, to serve as reference locations. The labels of all the markers used for this study include:

- $\quad$ Along the GT line: GTmain, GT15, GT30, GT45, GT60 and GT75

- Along the GTX line: GTXmain, GTX15, GTX30, GTX45, GTX60 and GTX75

- Axis Reference: Origin, X-Axis and Y-Axis

- Body Reference: Acromion, C7, Lateral Condyle and Sacrum

Each motion sensor yielded data in 3 components $-\mathrm{x}$, $\mathrm{y}$ and $\mathrm{z}$ axes. The visualization and real-time data logging of the motion capture process was enabled by the ODIN software installed in a windows-run PC. Data was sampled at $100 \mathrm{~Hz}$ to ensure accurate readings. Fig 3 illustrates the full trial set-up with a participant in a sitting posture, hoisted and having the markers attached. 


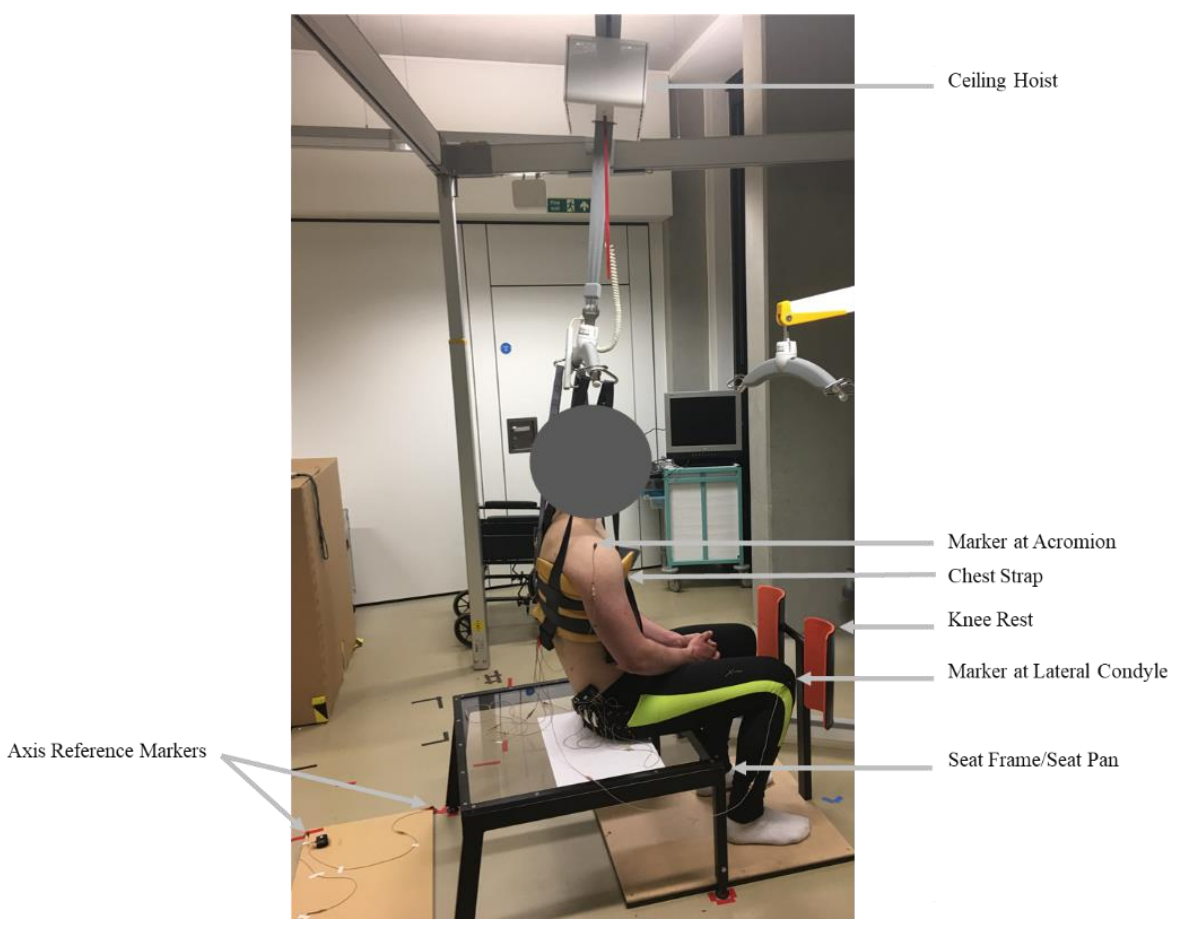

Fig. 3. The full trial set-up

\subsubsection{Trial Procedure}

The Codamotion system was calibrated and aligned before the start of the trial of each participant. Participants were asked to place their feet comfortably on the foot rest while locking their knees on the knee support provided. The motion capture recording was then initiated.

Participants were lifted gradually by the hoist controller till their buttocks were $30 \mathrm{~cm}$ off the seat surface. They were then lowered towards the seat surface until a slight contact was made between the buttocks and seat pan and left in this position for 5-10 seconds. This was called the 'First Contact' point. Then, they were fully lowered to the seat pan till their full weight was borne by the seat pan. This was called the 'Fully Deformed' point (Fig. 4). The difference between the first contact point and the fully deformed point in the z-axis was regarded as the 'degree of deformation' or simply Buttock Compression.

At a flat seat level (no angular inclination), 2-3 trials were conducted per participant, each lasting a maximum of 40 seconds. A trial was deemed successful if the movement recorded was vertical only. Trials where the movement was observed to include lateral or posterior shift were excluded. 


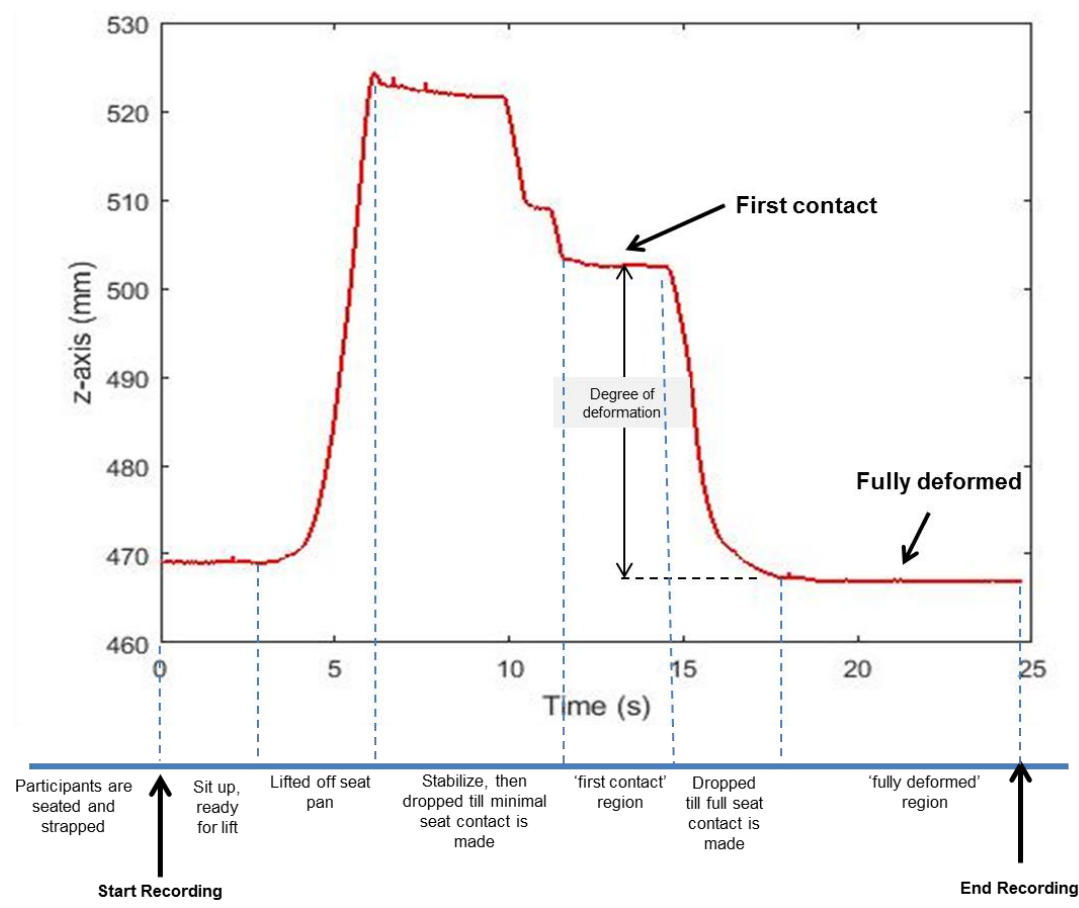

Fig. 4. Sample trial results for compression (z-axis) at GTmain

\subsection{Data Analysis}

Data analysis was performed using the IBM SPSS statistical package (version 24), Microsoft Excel and Matrix Laboratory (MATLAB). Anthropometric data collected were recorded in Excel spreadsheets while the trial data was exported from the ODIN software as text files and imported into MATLAB as cell arrays for further analysis. The results from the first 3 participants were regarded as pilots, to refine the data collection method, and were excluded from the final data.

In MATLAB, the z-axis data for the GTmain marker was plotted per trial for all participants, as shown in figure 5. Then, a start and end point within 'First contact' and 'Fully Deformed' were manually identified using the 'ginput' function. The time domains created were applied to other markers to acquire their corresponding values, and the average value per region was computed. Across marker locations on buttock, the numerical difference between the average value of the 'first contact' region and that of 'fully deformed' was regarded as buttock compression per trial. As the method was found to be repeatable, the average buttock compression values for both trials was the buttock compression per participant. If one out of two trials lacked buttock compression data at any of the locations due to marker occlusion, the value of the trial with data was repeated. If both trials had no readings, it was simply regarded as a missing value at that location.

Descriptive statistics such as mean, standard deviation (SD), coefficient of variation (CV) were calculated. A Shapiro-Wilks test was used to check for normality of the 
variables, with the level of significance set at 0.05 . Correlation analysis was performed to identify relationships between buttock compression and anthropometric variables.

\section{Results}

The mean, SD, CV, $5^{\text {th }}$ and $95^{\text {th }}$ sample percentile values, degrees of freedom (df) and Shapiro-Wilks normality values for all anthropometric measurements and buttock compression are shown in Table 2. The results represent values for 39 participants (31 males and 8 females). Out of all 43 variables analysed, 16 of them were found to not be normally distributed because they had values below the chosen significance level of 0.05 (Table 2).

As CV portrays the extent of variability in relation to the mean of the same variable, the CV for BMI, midaxillary, mid-thigh, medial calf was found to be larger $(>50 \%)$ than other measures, as they showed a wide variation in the population sample. Whereas, body dimensions such as height, sitting height, arm length and palm length had substantially lower $\mathrm{CV}$ values, in the order of 5-7\%. It was not surprising to find that the variables with relatively large $\mathrm{CV}$ values were found to have non-normal distributions while those with relatively smaller $\mathrm{CV}$ values were found to be normally distributed. Furthermore, it was worthy to note that all buttock compression variables exhibited a close degree of variability, having values between $22 \%$ and $27 \%$; which possibly implies a close relationship between these variables.

Due to marker occlusions and errors during data collection, some variables had missing values for some participants. This accounts for the numerical differences observed in ' $\mathrm{df}$ ' in Table 2. In computing the statistics, the option 'exclude cases pairwise' was selected in SPSS to prevent cases from being excluded from the analysis. Furthermore, the $5^{\text {th }}$ and $95^{\text {th }}$ percentiles of the population sample were included to show the variation within the sample.

As this was an exploratory study, the relationship between the variables was investigated using correlation analysis, to observe any distinguishable patterns. Though not all the variables were normally distributed, the Pearson correlation coefficient was adopted since the sample size was greater than 30 . The correlation coefficients between variables were computed in SPSS (Table 3), and scatter plots were plotted to visually identify patterns (Fig. 5). However, only correlation coefficients between buttock compression and anthropometric variables that were statistically significant (those that had a significance value below 0.05 ) and had correlation coefficients above 0.3 were reported for the purpose of conciseness.

\section{Discussion}

As there is no published data of such correlation analysis on buttock deformation and taking account of the biological variability of human tissues, correlations above 0.3 and below -0.3 were regarded as moderate correlations while those above 0.5 and below -0.5 were regarded as strong correlations and are highlighted in Table 3 . If the results of the correlation analysis are considered as a matrix of 12 buttock compression variables by 31 anthropometric variables, the total amount of possible correlations coefficients is 372 . 
Table 2. Descriptive Statistics and Test for Normality

\begin{tabular}{|c|c|c|c|c|c|c|c|}
\hline Measurement & $\begin{array}{l}\text { Mean } \\
(\mathbf{m m})\end{array}$ & SD & $\begin{array}{l}\text { CV } \\
(\%)\end{array}$ & $\begin{array}{c}\text { 5th } \\
\text { percentile }\end{array}$ & $\begin{array}{c}\text { 95th } \\
\text { percentile }\end{array}$ & df & $\begin{array}{c}\text { Sharpiro- } \\
\text { Wilks }\end{array}$ \\
\hline Age & 21.49 & 2.60 & 12.12 & 18.00 & 26.00 & 39 & 0.001 \\
\hline Mass & 75.22 & 12.79 & 17.01 & 54.80 & 97.09 & 36 & 0.268 \\
\hline Height & 179.72 & 9.33 & 5.19 & 160.43 & 196.42 & 36 & 0.687 \\
\hline BMI & 15.07 & 7.69 & 51.02 & 19.05 & 31.53 & 34 & 0.001 \\
\hline Percent fat & 23.51 & 3.68 & 15.63 & 5.30 & 30.63 & 34 & 0.038 \\
\hline Pectoral & 6.03 & 2.17 & 35.95 & 3.27 & 11.88 & 31 & 0.001 \\
\hline Midaxillary & 7.82 & 3.94 & 50.33 & 3.91 & 18.98 & 31 & 0.000 \\
\hline Biceps & 4.56 & 1.87 & 40.98 & 2.36 & 8.18 & 38 & 0.001 \\
\hline Suprailiac & 7.89 & 3.58 & 45.32 & 3.83 & 15.76 & 38 & 0.000 \\
\hline Abdominal & 13.47 & 6.08 & 45.17 & 5.48 & 26.74 & 38 & 0.019 \\
\hline Triceps & 9.96 & 4.27 & 42.81 & 4.26 & 19.13 & 38 & 0.020 \\
\hline Subscapular & 10.71 & 3.44 & 32.14 & 6.27 & 17.86 & 38 & 0.006 \\
\hline Mid-thigh & 15.86 & 8.10 & 51.05 & 5.12 & 32.42 & 38 & 0.035 \\
\hline Suprapatella & 10.23 & 3.89 & 38.05 & 5.56 & 20.13 & 38 & 0.001 \\
\hline Medial calf & 9.51 & 4.92 & 51.68 & 3.89 & 19.97 & 38 & 0.003 \\
\hline Posterior-suprailiac & 16.30 & 6.32 & 38.78 & 5.61 & 26.91 & 31 & 0.377 \\
\hline Lumbo-sacral & 15.48 & 7.74 & 49.98 & 5.47 & 33.13 & 31 & 0.025 \\
\hline Gluteal crease & 30.65 & 6.96 & 22.71 & 15.37 & 40.18 & 29 & 0.057 \\
\hline Waist girth & 779.71 & 71.08 & 9.12 & 669.50 & 900.50 & 38 & 0.138 \\
\hline Waist depth & 193.17 & 21.02 & 10.88 & 160.00 & 238.05 & 38 & 0.074 \\
\hline Waist breadth & 267.11 & 22.96 & 8.60 & 225.75 & 307.15 & 38 & 0.594 \\
\hline Hip girth & 991.71 & 76.67 & 7.73 & 889.50 & 1136.00 & 38 & 0.024 \\
\hline Hip depth & 235.12 & 21.08 & 8.97 & 203.65 & 267.50 & 38 & 0.208 \\
\hline Hip breadth & 346.26 & 24.23 & 7.00 & 311.90 & 398.95 & 38 & 0.099 \\
\hline Biacromial breadth & 424.69 & 31.53 & 7.42 & 363.70 & 472.10 & 37 & 0.276 \\
\hline Knee length & 616.56 & 44.47 & 7.21 & 547.20 & 705.00 & 35 & 0.209 \\
\hline Sitting height & 931.49 & 48.27 & 5.18 & 814.80 & 1002.20 & 35 & 0.240 \\
\hline Arm length & 789.31 & 41.59 & 5.27 & 730.00 & 861.00 & 35 & 0.157 \\
\hline Knee height & 545.86 & 34.67 & 6.35 & 489.40 & 610.00 & 35 & 0.678 \\
\hline Palm length & 194.34 & 10.77 & 5.54 & 174.40 & 212.00 & 35 & 0.451 \\
\hline Shoulder height & 601.03 & 42.18 & 7.02 & 518.00 & 665.90 & 33 & 0.685 \\
\hline GTmain & 33.69 & 7.66 & 22.74 & 18.82 & 47.11 & 39 & 0.868 \\
\hline GT15 & 36.90 & 8.54 & 23.14 & 22.35 & 50.45 & 39 & 0.410 \\
\hline GT30 & 41.76 & 9.68 & 23.17 & 24.89 & 58.25 & 38 & 0.800 \\
\hline GT45 & 43.94 & 10.71 & 24.36 & 24.92 & 61.32 & 38 & 0.976 \\
\hline GT60 & 45.07 & 9.97 & 22.13 & 26.29 & 64.68 & 36 & 0.780 \\
\hline GT75 & 43.68 & 10.51 & 24.06 & 27.56 & 65.94 & 37 & 0.536 \\
\hline GTXmain & 32.40 & 7.43 & 22.93 & 19.90 & 43.21 & 38 & 0.237 \\
\hline GTX15 & 37.06 & 8.67 & 23.38 & 21.66 & 48.39 & 38 & 0.013 \\
\hline GTX30 & 41.41 & 9.36 & 22.60 & 21.73 & 53.35 & 39 & 0.793 \\
\hline GTX45 & 42.98 & 9.82 & 22.85 & 28.78 & 60.06 & 36 & 0.581 \\
\hline GTX60 & 45.09 & 12.09 & 26.82 & 25.12 & 70.27 & 32 & 0.773 \\
\hline GTX75 & 46.48 & 10.32 & 22.20 & 29.07 & 65.49 & 34 & 0.699 \\
\hline
\end{tabular}


Table 3: Pearson correlation coefficient between buttock compression and anthropometric measurements

\begin{tabular}{|c|c|c|c|c|c|c|c|c|c|}
\hline $\begin{array}{c}\text { Buttock } \\
\text { Compression }\end{array}$ & Mass & $\%$ Fat & BMI & Pectoral & $\begin{array}{c}\text { Mid- } \\
\text { axillary }\end{array}$ & \multicolumn{2}{|c|}{ Suprailiac } & & $\begin{array}{l}\text { osterior } \\
\text { prailiac }\end{array}$ \\
\hline $\begin{array}{l}\text { GTmain } \\
\text { GT15 } \\
\text { GT30 } \\
\text { GT45 } \\
\text { GT60 } \\
\text { GT75 }\end{array}$ & $\begin{array}{l}.475 * * \\
.445 * * \\
.366^{*} \\
.400 *\end{array}$ & $\begin{array}{l}.534 * * \\
.403 * \\
.425 * \\
.372 * \\
.404 * \\
.504 * *\end{array}$ & $.424^{*}$ & $.362 *$ & $.407 *$ & \multicolumn{2}{|c|}{$.347 *$} & & $\begin{array}{l}500 * * \\
492 * *\end{array}$ \\
\hline $\begin{array}{l}\text { GTXmain } \\
\text { GTX15 } \\
\text { GTX30 } \\
\text { GTX45 } \\
\text { GTX60 } \\
\text { GTX75 }\end{array}$ & $\begin{array}{l}.576 * * \\
.467 * * \\
.437 *\end{array}$ & $\begin{array}{l}.577 * * \\
.423 * \\
.374 * \\
.550 * * \\
.527 * * \\
.411^{*}\end{array}$ & $\begin{array}{l}.431 * \\
.359^{*}\end{array}$ & $\begin{array}{l}.401 * \\
.361^{*}\end{array}$ & $.439 *$ & \multicolumn{2}{|c|}{$\begin{array}{l}.386^{*} \\
.365^{*}\end{array}$} & & $\begin{array}{l}568 * * \\
495 * *\end{array}$ \\
\hline $\begin{array}{c}\text { Buttock } \\
\text { Compression }\end{array}$ & $\begin{array}{l}\text { Mid- } \\
\text { thigh }\end{array}$ & $\begin{array}{l}\text { Gluteal } \\
\text { Crease }\end{array}$ & $\begin{array}{l}\text { Waist } \\
\text { Girth }\end{array}$ & $\begin{array}{l}\text { Waist } \\
\text { Depth }\end{array}$ & $\begin{array}{c}\text { Waist } \\
\text { Breadth }\end{array}$ & $\begin{array}{c}\text { Hip } \\
\text { Girth }\end{array}$ & $\begin{array}{r}\text { Hi } \\
\text { Dep }\end{array}$ & & $\underset{\text { Breadth }}{\text { Hip }}$ \\
\hline $\begin{array}{l}\text { GTmain } \\
\text { GT15 } \\
\text { GT30 } \\
\text { GT45 } \\
\text { GT60 } \\
\text { GT75 }\end{array}$ & $.343 *$ & $.507 * *$ & $\begin{array}{l}.496^{* *} \\
.426^{* *} \\
.330^{*}\end{array}$ & $\begin{array}{l}.462 * * \\
.453 * * \\
.408 * \\
.376 * \\
.438 * *\end{array}$ & $\begin{array}{c}.478 * * \\
.388 * \\
.325 *\end{array}$ & $\begin{array}{l}.656 * * \\
.559 * * \\
.553 * * \\
.470 * * \\
.486 * * \\
.584 * *\end{array}$ & $\begin{array}{l}.547 \\
.447 \\
.389 \\
.350 \\
.348 \\
.435\end{array}$ & & $\begin{array}{l}.581 * * \\
.502 * * \\
.469 * * \\
.397 * \\
.398 * \\
.490 * *\end{array}$ \\
\hline $\begin{array}{l}\text { GTXmain } \\
\text { GTX15 } \\
\text { GTX30 } \\
\text { GTX45 } \\
\text { GTX60 } \\
\text { GTX75 }\end{array}$ & $.340 *$ & $\begin{array}{l}.581 * * \\
.384 *\end{array}$ & & $\begin{array}{l}.520 * * \\
.433 * * \\
.357 *\end{array}$ & $\begin{array}{l}.467 * * \\
.350^{*}\end{array}$ & $\begin{array}{l}.725^{* *} \\
.601 * * \\
.351^{*} \\
.453^{* *} \\
.501 * * \\
.397^{*}\end{array}$ & $\begin{array}{l}.600 \\
.449\end{array}$ & & $\begin{array}{l}.635 * * \\
.530 * * \\
.394 * \\
.409 *\end{array}$ \\
\hline
\end{tabular}

**Correlation is significant at the 0.01 level (2-tailed)

*Correlation is significant at the 0.05 level (2-tailed)
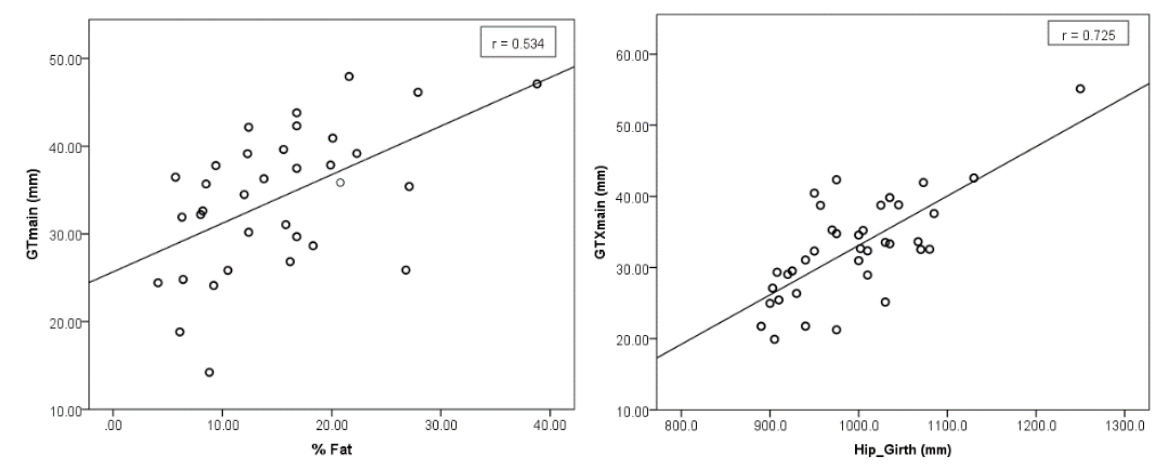

Fig. 5. Scatter plots illustrating the relationship between buttock compression and some anthropometric variables - \% fat and hip girth 
Out of this, 99 correlation coefficients were found to be statistically significant, having a moderate correlation strength at the very least. This means that these correlations did not occur by chance and indicates the presence of a relationship in the actual population. It is important to note that there were only 3 negative correlations coefficients out of 372 total correlations, and they were not found to be statistically significant.

It was observed that 11 anthropometric variables that did not have any statistically significant correlations with buttock compression; hence, they were absent from results in Table 3. They include age, height, biceps, triceps, subscapular, medial calf, sitting height, arm length, knee height, palm length and shoulder height. Out of the remaining 20 anthropometric variables, 9 of them were observed to have statistically significant and both moderate/strong correlations with at least 5 buttock compression variables. Furthermore, considering that there are 12 buttock compression variables, the following 6 anthropometric variables had the highest number of positive and moderate/strong correlation coefficients with them: mass (7), waist depth (8), hip depth (10), hip breadth (10), hip girth (12) and \% fat (12). Hip girth revealed the highest correlation coefficients of 0.656 and 0.725 at GTmain and GTX marker location respectively. This provides a scientific basis for the theory that a bigger buttock size equals a bigger range of compression. Hence, $\%$ fat and hip girth measurements are closely related to buttock compression at all 12 locations investigated.

As fat is known to be stored around the hip and waist areas, it can be deduced from the results of this correlation analysis that buttock deformation is more of a function of the adiposity of the human being than the muscularity. Also, it was revealed that for this population sample, a relatively higher degree of buttock compression was experienced rearwards than around the actual GT.

\section{Conclusion}

This study provided insightful results into relationship between buttock deformation and anthropometric variables. It showed that $99.19 \%$ (369 of 372) of all possible correlations observed were positive in nature, and that $26.12 \%$ (99 of 372) of all correlations were statistically significant. Hence, they were representative of the actual human population, from a statistical perspective.

As buttock deformation values were taken from the right side of the human body, there remains the question of asymmetry between both sides of the buttock, which would be explored in future studies. Currently, an investigation into the 3D buttock deformation to include the compression, anterior-posterior spread and lateral spread is in progress. The results from this study and future studies would lead to achieving a predictor model for buttock deformation based on anthropometric variables and seat characteristics, which would be applicable to DHM and beneficial to seat manufacturers. 


\section{References}

1. S. E. Sonenblum, S. H. Sprigle, J. M. K. Cathcart, and R. J. Winder, "3-dimensional buttocks response to sitting: A case report," J. Tissue Viability, vol. 22, no. 1, pp. 12-18, 2013.

2. P. Vink and D. Lips, "Sensitivity of the human back and buttocks: The missing link in comfort seat design,” Appl. Ergon., vol. 58, pp. 287-292, 2017.

3. Statistica. (2019). Global car sales 1990-2018 [online]. Available at: https://www.statista.com/statistics/200002/international-car-sales-since-1990/ [Accessed 27 Jan. 2019].

4. ATAG. (2019). Facts \& figures [online]. Available at: https://www.atag.org/factsfigures.html [Accessed 27 Jan. 2019]

5. G. Kyung, M. A. Nussbaum, and K. L. Babski-Reeves, "Enhancing digital driver models: Identification of distinct postural strategies used by drivers," Ergonomics, vol. 53, no. 3, pp. 375-384, Mar. 2010.

6. T. Patel, J. Sanjog, A. Chatterjee, and S. Karmakar, "Statistical Interpretation of Collected Anthropometric Data of Agricultural Workers From Northeast India and Comparison With National and International Databases," IIE Trans. Occup. Ergon. Hum. Factors, vol. 4, no. 4, pp. 197-210, Oct. 2016.

7. M. M. Verver, J. van Hoof, C. W. J. Oomens, J. S. H. M. Wismans, and F. P. T. Baaijens, "A Finite Element Model of the Human Buttocks for Prediction of Seat Pressure Distributions," Comput. Methods Biomech. Biomed. Engin., vol. 7, no. 4, pp. 193-203, Aug. 2004.

8. M. Grujicic, B. Pandurangan, G. Arakere, W. C. Bell, T. He, and X. Xie, "Seat-cushion and soft-tissue material modeling and a finite element investigation of the seating comfort for passenger-vehicle occupants," Mater. Des., vol. 30, no. 10, pp. 4273-4285, Dec. 2009.

9. T.-H. Kim, Y.-T. Kim, and Y.-S. Yoon, "Development of a biomechanical model of the human body in a sitting posture with vibration transmissibility in the vertical direction," Int. J. Ind. Ergon., vol. 35, no. 9, pp. 817-829, 2005.

10. J. M. Porter, D. E. Gyi, and H. A. Tait, "Interface pressure data and the prediction of driver discomfort in road trials," Appl. Ergon., vol. 34, no. 3, pp. 207-214, 2003.

11. C. W. J. Oomens, O. F. J. T. Bressers, E. M. H. Bosboom, C. V. C. Bouten, and D. L. Bader, "Can Loaded Interface Characteristics Influence Strain Distributions in Muscle Adjacent to Bony Prominences?," Comput. Methods Biomech. Biomed. Engin., vol. 6, no. 3, pp. 171-180, 2003.

12. R. M. A. Al-Dirini, M. P. Reed, and D. Thewlis, "Deformation of the gluteal soft tissues during sitting," Clin. Biomech., vol. 30, no. 7, pp. 662-668, 2015.

13. K. M. Moerman et al., "Computer Methods in Biomechanics and Biomedical Engineering On the importance of 3D, geometrically accurate, and subject-specific finite element analysis for evaluation of in-vivo soft tissue loads On the importance of 3D, geometrically accurate, and subj," Biomech. Biomed. Eng. Comput. methods Biomech. Biomed. Eng., vol. 20, no. 5, pp. 483-491, 2017.

14. S. Hiemstra-van Mastrigt, L. Groenesteijn, P. Vink, and L. F. M. Kuijt-Evers, "Predicting passenger seat comfort and discomfort on the basis of human, context and seat characteristics: a literature review," Ergonomics, vol. 0139, no. May 2017, pp. 1-23, 2016.

15. R. Marshall et al., "Design and evaluation: End users, user datasets and personas," Appl. Ergon., vol. 46, no. PB, pp. 311-317, 2015.

16. P. van der Meulen and A. Seidl, "Ramsis - The Leading Cad Tool for Ergonomic Analysis of Vehicles," in LNCS, vol. 4561, 2007, pp. 1008-1017.

17. M. Damsgaard, J. Rasmussen, S. T. Christensen, E. Surma, and M. de Zee, "Analysis of musculoskeletal systems in the AnyBody Modeling System," Simul. Model. Pract. Theory, vol. 14, no. 8, pp. 1100-1111, 2006.

18. H. T. E. Hertzberg, "The conference on standardization of anthropometric techniques and terminology (a report)," Am. J. Phys. Anthropol., vol. 28, no. 1, pp. 1-16, Jan. 1968.

19. "Codamotion." [Online]. Available: https://codamotion.com/. [Accessed: 27-Jan-2019]. 